\title{
A new hypothesis for explaining Japan's prolonged financial slump: Mismanagement of audience effects
}

\author{
Yasushi SUZUKI*
}

This paper explores a new hypothesis that can help to shed light on why the Japanese financial system has fallen into a unique transition failure in terms of its extraordinarily prolonged financial slump. An aspect of the continuing Japanese financial slump can be explained in terms of games that were being played between regulators and main banks as each tried to test the intentions and commitment of the other in a context where the traditional system of monitoring had collapsed together with its relationships of trust. Higher "audience costs" which prevented the restoration of appropriate relations between regulators and banks, associated with the internal collapse of trust in the system, can explain this unique transition failure.

\section{Introduction}

We take it as uncontroversial that the core objectives of banking regulation are (1) to ensure financial stability and (2) to promote sound financial intermediation. Banking regulation has to balance the task of maintaining and enhancing the roles of banks (lenders) as financial intermediaries and monitors for allocating financial resources, and that of preventing them from undertaking non-performing credits under conditions of uncertainty in credit risk assessments. At the same time, regulators have to prevent contagious runs through the policy for protection, without creating adverse incentives for banks that may lead to a failure of effective monitoring and moral hazard. Here, we should note that banking regulators, virtually in any type of financial structure, are very closely involved in the operation of banks, in order to retain the effective power to monitor and discipline them for regulatory purposes. As the regulation economic school emphasizes, banking regulation is of capital importance because of its effect both on the behaviour of bank managers and on the specific characteristics of the banking industry (Freixas and Rochet 1997, 257). Indeed, more or less extensive banking regulation exists in virtually every country with a well-developed banking system.

\footnotetext{
* Yasushi Suzuki is professor of management studies at the Graduate School of Management, Ritsumeikan Asia Pacific University, Japan (Email: szkya@apu.ac.jp).
} 
Japan's economic and financial slump has been prolonged and deep, though Japan's financial deregulation was almost complete in 2001 after the financial "Big Bang". We know this made a very limited contribution to bailing the Japanese banks and the Japanese economy out of the prolonged stagnation. The credit crunch problem particular to those small and medium enterprises (SMEs) that rely their funding heavily on bank loans continues. Despite the fact that the Japanese SMEs play an important role in the economy ${ }^{1}$, the outstanding loans to SMEs had dropped sharply from JPY 345 trillion in December 1998 to JPY 260 trillion in December 2003, then to JPY 256.9 trillion in December 2006. The trend in the balance of loans from banks to SMEs and a continuous year-on-year decline can be observed since the second half of 2007, staying at no more than JPY 260 trillion (JSBRI 2009). Clearly, the Japanese banks were very conservative when it came to assessing the credit risks of SMEs.

The argument in this paper has implications for such explanations of Japan's prolonged and deep financial slump. Many economists suggest that the Japanese financial slump was the result of of the macroeconomic policy errors of regulators throughout the 1990s and onward, causing Japan's banking crisis and subsequent prolonged economic stagnation (for instance, Yoshikawa 1999 and 2003; Patrick 1998; Saito 1998; Takeda 2001; Cabinet Office 2001; Harada 1999; Hoshi and Kashyap 2001; Tsuru 2006; Ikeo 2006). Explanations that put much of the blame on the Ministry of Finance as the regulator for persistent failures of omission and commission are insufficient ${ }^{2}$. These theories fail to explain why policy errors apparently continued over such a long period. This paper explores a new hypothesis that can help to shed light on why the Japanese financial system has fallen into a unique transition failure in terms of its extraordinarily prolonged financial slump. Why did the Japanese convoy ${ }^{3}$ system between the regulators and the regulated banks fail to find a well-working alternative financial system? We argue that higher "audience costs" which prevented the restoration of appropriate relations between the regulators and the regulated, associated with the internal collapse of "trust" in the Japanese convoy system, can explain the transition failure that prevents the Japanese financial system from responding to the obvious failings of its financial structure. We review how the convoy was collapsed so as to improve the link between theory (mainly new institutional approaches) and empirical observation on the collapse of the convoy and its after-effects.

Section 1 provides an overview of the concepts of "trust" on which New Institutional Economics sheds analytical light as variables determining transaction costs. We discuss the characteristics of "trust" observed in the traditional Japanese monitoring system. Section 2 aims to point out an intangible and informal institutional feature of the convoy monitoring system which limited a negative "audience effect". Section 3 examines how intensified audience effects could induce the Japanese regulators to ruth- 
lessly let the Japanese banks go bust. In other words, this was the transition cost the regulators paid. Section 4 surveys the theories exploring the relationship between transaction costs and informal institutions. We use this to examine the nature of the "transition failure" into which the Japanese monitoring system has fallen. Section 5 concludes.

\section{Trust}

Both Francis Fukuyama in his book Trust: The Social Virtues and the Creation of Prosperity and Ronald Dore in his many writings on Japan (Dore 1998; 2000) argue that Japan has been a "high-trust", "group-oriented" society. Interestingly, there is a difference in their categorization of the United States, which is not directly relevant for our narrative. According to Dore, the United States can be categorized as an individualistic country at one extreme while Japan is a group-oriented one at the other. In contrast, Fukuyama regards both countries as high-trust and group-oriented ${ }^{4}$ (Fukuyama 1995).

There existed deep but intangible and informal institutional arrangements in the traditional Japanese financial and monitoring system. In particular, (1) the dense networks of communication in the Japanese "main bank ${ }^{5}$ " system, where the main banks (lenders) were deeply involved as quasi-insiders in the operation of client firms (borrowers), and (2) the dense information networks in the "convoy" monitoring system between the regulators and the regulated banks, both contributed to stabilising irrational swings of uncertainty and to the effective allocation of financial resources during Japan's high growth. In this group-oriented financial monitoring system which was part of the system described as "Japan Incorporated", the main bank had the task of assessing client firms' credit risks and the degree of uncertainty they were exposed to. At the same time, the main bank's role was supported by the whole system including firms and regulators. One problem with this system was that when the system became exposed to a higher degree of risk and uncertainty that was beyond the capacity of Japan Incorporated to absorb, the fragility of the "group-oriented" system dramatically increased.

In the traditional Japanese mode of monitoring, the role of trust was to reduce the cost of monitoring. The cost of monitoring is an important component of transaction costs. While the transaction cost is defined as the economic equivalent of friction in physical systems (Williamson 1985), we assume that trust may, not always but fairly often, play the role of lubricant for making the economic system run smoothly. Risks of Williamsonian "opportunism" can be reduced by mutual trust (Arrow 1974, 23). But also, without wishing to stretch the metaphor too far, the wrong type or amount of lubricant can also sometimes make systems fail.

Trust has been referred to as "attitudes and behaviour which indicate that each person is willing to rely on the other to act fairly and to take into account the other's wel- 
fare", as "solidarity", and as "a belief in future harmonious affirmative cooperation" (Cohen and Knetsch 1992). Contract negotiations and performance will likely take place more effectively if trust is present and is generated by the process. Fukuyama (1995), referring to what the sociologist James Coleman has called "social capital", argues that the ability of people to work together for common purposes in groups and organizations and their ability to associate with each other depends on the degree to which communities share norms and values and are able to subordinate individual interests to those of larger groups. "Out of such shared values comes trust" (Fukuyama 1995, 10).

One of the invaluable insights of Francis Fukuyama and Kenneth Arrow is to point out that trust has a large and measurable economic value and has an important bearing on economic organization. "Ethical elements enter in some measure into every contract; without them, no market could function. There is an element of trust in every transaction; typically, one object of value changes hands before the other one does..." (Arrow 1974, 24).

However, since operationalizing trust, however it is defined, has proved inordinately difficult (Williamson 1985, 406), analysis of the variable is still limited. Arrow insists that the efficacy of alternative modes of contracting and monitoring would vary among cultures because of differences in trust. Due partly to the popularity of Fukuyama's definition of trust, some political economists in the Anglo-American tradition were interested in analyzing trust relations in the Japanese economic system. On the contrary, the Japanese themselves tended to be preoccupied with what they see as the problem of an excess of trust (Dore 2000, 81). To some extent, cultural factors are related to the degree of trust relations. However, we would say that the degree of trust even in a particular culture or society could rather vary. "Most of us operate in some middle realm where we admit social claims, sometimes forget about them for long stretches of time as we go about our daily private roles, sometimes rise to an occasion, sometimes fall miserably short, as we assert our individuality in contexts that are not totally appropriate" (Arrow 1974).

To understand the Japanese financial system in its traditional mode, the problems it faced and the subsequent transition failure, we need to examine in greater detail the type of "trust" which was underpinning the mode of monitoring in the traditional Japanese banking system. The key characteristics of trust in this mode appear to be as follows:

a) Trust between banks and firms: (i) The deep involvement of the main bank in the operation of the client firms contributed to strengthen the lender's confidence and relationships of trust between borrower and lender. Repeated transactions and a long-term relationship enhanced the "trust" of the lender in the credibility of the borrower, in the sense that the borrower would not shirk from efforts at running its 
business and would not take opportunistic actions against the lender. Based upon the creation of such "trust", the cost of monitoring through formal international arrangements was significantly reduced. (ii) Firms put in a high level of effort in running their businesses to sustain the trust of the main bank. The lender's trust was a valuable 'commodity' that enabled firms to expect financial support from the main bank, including stable credit lines for investment and working capital as well as rescue operations if a firm got into temporary trouble. (iii) Both parties realized that a failure to meet the other's expectations would hurt their "reputation" not only bilaterally, but also in the broader financial world. The enforceability of formal and informal contracts in this monitoring system based upon mutual trust was strong precisely because of the high costs of losing reputation and franchise value (see Hellmann et al. 1997; Stiglitz 1994).

b) Trust between regulators and banks: In the "convoy" monitoring system based upon a protection and sanction mechanism, (i) The dense information network between banks and regulators contributed to create regulators' trust in the banks, at least in the sense that the banks in trouble could be expected to promptly report the situation through a non-public route for sharing information. On the one hand, prompt responses by regulators had an effect of ensuring financial stability. On the other hand, this mode of information sharing based on preserving trust prevented the banks, in particular the main banks, from shirking their monitoring efforts as long-term monitoring agents of client firms. Their failure to sustain regulators' trust would have an economic cost if the loss of reputation and relationship with regulators deprived them of bank rent opportunities ${ }^{6}$ coming from their role as a main bank. (ii) The banks also trusted the regulators to play a guiding role and to display ex-post flexibility in making new policies and enforcing them to sustain the financial system and thereby the trust both sides had developed. As a result, there was an expectation in the banking industry that the regulators would be benevolent to the banks even in unexpected adverse situations.

The important point was that mutual trust played an important role as a lubricant restraining the transaction costs of contracting and monitoring in the traditional Japanese "relation-based" financial system. It follows that the outcomes observed in the Japanese "relation-based" financial system were sensitive to the degree or changing nature of trust, a commodity that is fundamentally non-quantifiable. Dore (1998) refers to "systemic cohesion" as a feature of the Japanese model that comes from what one might call "psychological consonance". He identifies the following behavioural dispositions within the system; (i) the willingness to enter into binding long-term commitments, implying a very moderate degree of liquidity preference; (ii) greater concern for long-term stable 
rewards than for short-term gains; (iii) a concern for the emotional and moral quality of the social relationships involved in economic transactions, the friendships and the mutual obligations they generate, as well as their material profitability; (iv) a tendency to view group solidarity as an important ingredient of that emotional and moral quality the relevant "group" being, depending on context, one's department, one's firm, one's industry, one's nation, Japan; (v) the egalitarian perception that group solidarity becomes impossible if inequalities, either of material reward or of respect, become too wide (Dore 1998, 777).

\section{A mechanism that limited the negative audience effects}

Which financial policy is best suited to achieve financial stability has been controversial. Barry Eichengreen emphasized the prevention of financial crisis in his book Toward $A$ New International Financial Architecture (1999). As a key prescription for preventing crises, he focussed on the "disclosure of information" that was expected to attenuate asymmetries of information among regulators, banks and borrowers, which would in turn strengthen "market discipline" and help policymakers to identify the need for corrective action (Eichengreen 1999, 10; see also Basel Committee on Banking Supervision 2006). Many analysts in Japan would agree with this emphasis on promoting the disclosure of information. However, does the disclosure of information always help?

Banking is an information intensive industry, which looks at the financial transactions, cash-flow history and ongoing credit relationships of a borrower. The intangible and tacit nature of much of the information relevant for assessing a borrower's promise to repay makes it almost impossible to transmit all of this information in any simple way to markets or other lenders through codified signals. Thus, bank defaults and the systemic risk of potential contagious runs cannot be prevented or resolved by the ordinary auction market mechanism. Therefore, financial regulations and government intervention for prevention are critical to maintain financial stability. Taking the specific nature of information in financial markets into consideration, how should the information pertinent for assessing the potential solvency or insolvency of banks be dealt with? An interesting argument by Shanker Satyanath in the context of the 1997 Asian banking crisis draws attention to the complexity and constraints in the unfettered disclosure of information.

In countries whose political-economic institutional arrangements include reliable private channels of communication from domestic private banks to the government, monetary policy decision makers will rationally accommodate in- 
formation about the near insolvency of banks in their interest rate choices..... With regards to the counterfactual, where private channels are unreliable, domestic private banks will risk costly bank runs if they try to communicate that they are on the verge of bankruptcy, since this information is potentially observable by the public. (Satyanath, S., in Elster 2000, 36-37. Some phrases are omitted from the original).

Jon Elster (2000) asserts that a crucial lesson is the reliability of private channels enabling the agent (banks) to inform the regulator without simultaneously informing the public. Such reliable and closed channels are very important for financial systems to make it possible to detect problems and try to resolve problems of bank solvency before the bank actually becomes insolvent. The disclosure of information between regulators and banks would not always be efficacious as it is conditional on what Elster calls "audience effects" by which "one can impose costs on oneself by announcing publicly that one is going to quit, thus raising the stakes by adding shame and loss of prestige to the other costs of relapse" (ibid., 69). Nishimura (1999), who was appointed Chief Director of the Banking Bureau in the Ministry of Finance (MOF), points out such a dilemma. In 1995, the MOF announced that the amount of non-performing loans held by the Japanese banks had reached around JPY 40 trillion, while it had been previously announced to be only around JPY 13 trillion. This was because of a change in the definition and scope of non-performing loans to include not only loans where repayments had been suspended but also loans where interest rates has been reduced or exempted. In addition, the scope of the definition was extended to include not only the 21 major banks but also all depository institutions. This disclosure per se was reasonable. However, as Nishimura (1999) points out, this sudden announcement triggered deeper public uncertainties over the disclosure process of the MOF, consequently fuelling general public distrust in the financial system.

Needless to say, a protective structure between banks and banking regulators can also result in potential moral hazard problems. As referred to earlier, the regulatory structure has to keep banks as well as the regulators from abusing their powers to their own advantage. How do financial systems deal with these delicate relations? In the case of the United States, although the role played by US banks is largely limited to lending short-term for working capital, the regulators held to the traditional conservative strategy of enforcing tight capital adequacy requirements and disclosure rules on banks to prevent bank runs. This structure has limited the negative audience effect of disclosure of information related to the insolvency of banks, even when they occasionally occur. Although an affected bank may be insolvent, the macroeconomic impact would be limited, because the financial role played by the US banks was quite limited within this 
structure, where the US banks were encouraged not to have large commitments and exposures to particular companies or groups. In contrast, given the Japanese banks' predominance in corporate funding in Japan, the increasing pressure on disclosure of information exposed the Japanese banking system to higher economic and political risks due to audience effects.

In its heyday, the Japanese relation-based banking system was based on closed ("not public") channels for sharing information, and this allowed efficient information transmission between regulators and quasi-insiders, beyond the ordinary transmission between the regulator and the regulated. The private and closed channel for sharing information in the "convoy" system was based upon specific Japanese social networks and relationships connecting the financial establishment in Japan. On the one hand, the major Japanese banks, in particular the long-term credit banks that were established to mediate long-term funds for the reconstruction of social and economic infrastructure, used to attract the educational elite of the country. Long-term credit banks, in particular the Industrial Band of Japan (IBJ), had accumulated substantial human resources for monitoring projects and managerial decision-making in firms, since the IBJ had been instrumental in the channelling of public funds to targeted military industries in the pre-war period (Aoki et al. 1994, 33). During the post-war and catching-up period, the regulators and the selected banks, in particular the IBJ and the major banks, worked together as quasi insiders and contributors to revitalizing "Japan Incorporated". On the other hand, the Japanese major banks aggressively recruited the educational elite of reputable universities as an important investment in human resources and this sustained the financial establishment over time. For instance, Okazaki (1995) reports that more than $20 \%$ of the new graduates from the School of Economics, University of Tokyo entered the banking industry after the late-1960s. This share was equal to the share entering manufacturing firms. The Long-Term Credit Bank of Japan (LTCB, one of the long-term credit banks) hired 53 persons as new graduates in 1986, of whom 43 had graduated from the five leading universities; University of Tokyo, Hitotsubashi University, University of Kyoto, Keio University and Waseda University. Many of these elite recruits were assigned to critical positions where they were contact points with the MOF and could communicate with individuals of similar backgrounds within the government. The appointment of the so-called MOF-tan, who was in charge of contacting and being contacted on an almost daily basis for sharing information or lobbying with the MOF, was considered as a path to the top elite in the bank, promising further promotion. The major roles of the MOF-tan were as follows:

(1) To provide information on demand by the MOF officials.

(2) To collect and analyze information from the MOF officials for predicting the direc- 
tion and change of financial policies and regulations.

(3) To informally negotiate preliminary drafts of amendments and supplements to existing regulations.

(4) To lobby for necessary approvals or for accommodations. Patrick (1998) points out that a "convoy" system was maintained whereby the assets of all banks grew at about the same rate and their relative rankings did not change over time.

(5) To monitor the schedule and strategy of the Inspection team. This task was particularly important and relevant for the relationship system. Its importance stemmed from the fact that the Inspection Division (Kensabu) of the MOF's Banking Bureau retained the power of effectively disciplining banks. On the other hand, the fact that it was a closely managed process shows how effectively relationships were used to avoid high transaction cost confrontations, and to allow banks enough time to prepare for inspections in the form of voluntary disclosures.

In spite of the success of the relation-based mode of banking in the past, the question arises of why the Japanese banking regulators were caught out during the 1997-98 financial crisis. Why did the Japanese regulators fail to provide proper guidance or use ex-post flexibility to overcome specific problems in the post-bubble period? Though they had been informed of the near insolvency of some large banks, why did the regulators opt for the apparently ruthless policy of letting those banks go bust, instead of assisting them to overcome problems as in the past? We will turn to these questions in the next section.

\section{Intensified "audience" effects}

This section examines the politics surrounding the regulators' decision to ruthlessly abandon major banks without examining all the economic implications to try to determine why Japanese regulators changed over so conclusively to an attempt to develop an Anglo-American rules-based system of supervising in Japan. We argue that the regulators' failure to properly respond to Japan's financial crisis can be explained according to the logic of "audience effects". This logic proposes that regulators' decisions were increasingly constrained more by public opinion, in particular, by general public distrust in the financial system that intensified in the 1990's due to the series of performance failures and scandals addressed below.

The traditional Japanese convoy system where regulators and the banking industry enjoyed closed (not public) channels for sharing information has been controversial, because this structure could in theory explain unproductive rent-seeking and therefore 
the crisis of the Japanese financial structure. In fact, there were "the long-established conventions of entertainment of the regulators by the regulated - 'relational regulation', as it were, paralleling relational banking" that limited unproductive rent seeking (Dore 2000, 158-159). However, after the collapse of the "bubble" economy, the populist media, including intelligentsia and opinion leaders, began to attack the relationships between banks, the MOF and the political establishment. These attacks, beginning around 1991, focused on exposing a series of scandals related to illegal loans by Japanese banks. Examples were the scandal of illegal loans by Sumitomo Ban (later the Sumitomo-Mitsui Financial Group) to the Itoman Corporation around Spring 1991, suspicions over illegal loans by Fuji Bank (Mizuho), Kyowa-Saitama Bank (Resona) and Tokai Bank (Mitsubishi-UFJ) in July 1991 respectively, and suspicions about illegal deposits by Toyo Credit involving the Industrial Bank of Japan (Mizuho) in August 1991. In addition, a scandal over cover-ups and market manipulation by Nomura Securities, the top securities house, was exposed around June 1991. Initially, the media accused banks of incompetence. But soon, the "claim to elite incorruptibility (was) badly dented, in part by one or two spectacular revelations of personal corruption on the part of senior officials - clear examples of personal enrichment or the enrichment of friends, through the abuse of power" (ibid., 158). Needless to say, any corrupt official illegally leaking secrets leading to the abuse of power was to be blamed. However, the manipulative reports by the media and intelligentsia resulted in a public outcry that failed to calmly assess the essential benefits and defects of the relation-based financial system in the context of Japan. "Newspapers report the size of the restaurant bills turned up by the prosecutors investigating cases of bank fraud, but rarely relay the bureaucrat's defence: 'Our decisions are not swayed by feasting and golf course treats, which we receive in moderation from all participants equally; but they are essential ways in which we get to learn informally the problems of the industry; they serve to establish the relations of trust which enables Japan to have reasonably honest banking with only 400 bank inspectors, a tenth of the number in the United States..."' (Dore 2000, 159). The media and intelligentsia focused on the negative aspects that occasionally surfaced due to the exclusiveness of the relationships underpinning the convoy system without looking at the positive aspects which resulted in an effective monitoring system based on low aggregate monitoring costs. The challenge for Japan was to reform this system and build on aspects that were appropriate for the new monitoring and regulatory challenges as Japan changed from a catching up economy to a frontier economy as is argued later. Instead, the public outcry simply concluded that deregulation in terms of a transition to an Anglo-American financial system was the answer.

The more the media dramatized the stories of "the few bad apples in every barrel which were always there" (Dore 2000), the higher the "audience cost" was in Japan. 
Nishimura (1999) quotes a senior colleague's comment when he was appointed as Chief Director of the Banking Bureau in the MOF in 1994; "In the past, the public supported whatever the MOF did, because the public trusted that the MOF protected the national interest. After the exposure of a series of scandals over cover-ups and market manipulation by major securities companies in 1991, the public would no longer accept that whatever the MOF did was in the national interest." Nishimura points out that this was a turning-point for the MOF.

The old relationships between the MOF and the banking sector that had enabled efficient monitoring at relatively low monitoring cost began to rapidly unwind. The MOF publicly stated that it would not provide rescue options for financial institutions that could not survive the process of deregulation. The audience effect on the process of financial deregulation in Japan intensified after the arrival, in 1993, of the first coalition government of Prime Minister Hosokawa. This was when Japan's ruling Liberal Democratic Party, the LDP, lost power after a 38-year reign. The Hosokawa government had to tackle a range of difficult political issues, including the conclusion of the GATT Uruguay Round of trade negotiations that resulted in the opening up of the Japanese rice market despite strong resistance from the powerful agricultural interest groups and politicians who represented rural areas. The government also had to address issues of electoral reform at home while trying to lead an unprecedented coalition of eight political groups with a wide range of conflicting political ideas. In this context, dealing with the non-performing loan problem was not the most important priority on the political agenda.

The deregulation of the deposit rate ceiling was completed as scheduled in October 1994. Also in December 1994, the retiring president of the BOJ publicly announced that the bankruptcy of some small banks with financial difficulties would be unavoidable and possibly desirable (see Okuno-Fujiwara 1997, 375). Two credit cooperatives soon fell into this category in 1994: the Tokyo Kyowa Credit Cooperative and the Anzen Credit Cooperative. Instead of enabling one of the major Japanese banks to take over the smaller banks, the Tokyo Kyodo Bank was established through a capital injection by the Bank of Japan. This signalled the end of the role of the major Japanese banks as 'white knights' even under initiatives of the MOF, a role that had been significant for bailing out collapsed middle-sized financial institutions though the merger and acquisition process under the "convoy" system. Another example of new approaches which challenged old relationships was the suspension of new deposit taking and lending operations for Cosmo Credit Cooperative and Kizu Credit Cooperative in 1995.

Then, in June 1996, the Diet passed six laws establishing the Housing Loan Administration Corporation and the Resolution Collective Bank to cope with the liquidation of failed jusen (housing loans) companies and credit cooperatives. The growing 
public dissatisfaction with the injection of 685 billion yen of public funds for resolving the jusen problem, together with their pessimistic sentiments during the prolonged recession made MOF officers as well as the MOF-tan in banks hesitate in revitalizing this sector using existing institutional arrangements and relationships. Okuno-Fujiwara (2002, 77-79) criticizes the public and media response as misleading, and argues that economists including himself should have articulated the necessity of a quick resolution of the jusen problem because delays here held back the government and the banking industry from dealing with the non-performing loan problem. Nishimura makes an interesting comment in this context: "the MOF did not intentionally postpone its response to the collapse of the bubble economy, but it is better to admit that the MOF had little capacity of taking pre-emptive action. Such a policy would possibly result in serious criticisms and strong political leadership would be required to support the policy as a necessary one for Japan's future. The political leadership would have to deal with the public outcry and agitation. However, who could put up with this? Foreign pressure has been one political-economy device for executing these types of difficult policies because no-one (in Japan) could be blamed. However, this case was too big and complicated to use such a political-economy device" (Nishimura 1999, 89). Meanwhile, a series of earlier scandals in which MOF officials warned banks of forthcoming inspections was revealed in March 1998. Four officers of the ministry were arrested, and their superior, Yoichi Otsuki, hanged himself in humiliation in January of that year (Kindleberger 2000, 87).

By mid-1998, when the issue of how to bail out the collapsed LTCB became controversial in the parliament as a political rather than an economic issue ${ }^{7}$, the MOF had been sidelined as the core agency dealing with financial problems. Nishimura (1999) points out that the lessened presence of the MOF was due mainly to a series of scandals involving MOF officials fuelling a public outcry against the MOF. Uriu (1999) points out that with public attention focusing on their past failures, bureaucrats had strong incentives to avoid further policy mistakes: absent strong political leadership and direction, bureaucrats were reluctant to advocate bold actions or solutions. Toya (2003) insists that the political economy situation related to the Japanese financial Big Bang (financial deregulation) can be the most properly explained by the rationale of actors seeking the survival of their organizations. In particular, he points out that when an actor lost the public trust, receiving trust became the main motivation for the actor. This claim implied that actors would respond to public opinion even if this had drastic and adverse effects on the relationships of trust between agencies on which the financial system was based. The above described series of policy errors and scandals resulted in a loss of public trust in the MOF's role of designing and monitoring the Japanese financial system. In addition, a series of scandals over the banking industry (for instance, illegal 
compensations for corporate extortionists (so-kai-ya) by Nomura Securities and Dai-ichi Kangyo Bank exposed around March 1997) resulted in a loss of public trust in the banking industry. Together, these resulted in higher audience costs, which prevented the restoration of appropriate relations between the regulators and the regulated. This environment of collapsing trust provides a context for understanding financial regulators' apparent abdication during the 1997-98 financial crisis and the subsequent prolonged financial slump, and for their headlong acceleration of the financial "Big Bang" deregulation causing further adverse effects on the Japanese financial sector.

\section{Costs of abandoning the traditional mode - The transition cost}

When monitoring institutions do not work efficiently, why do they not change rapidly? The general answer is that the emergence of new institutional arrangements that can reduce transaction costs can be constrained by the higher-level transaction costs of organizing the change process itself. Khan (1995) points out that transition can also be blocked by political constraints if change in particular directions is strongly resisted by powerful groups who stand to lose. According to Khan (1995, 72-73), institutional failure can therefore occur at two levels; "structural failure" and "transition failure". The former refers to the performance of an existing set of institutions and the latter to the efficiency of the process through which inefficient institutions are changed. "Structural failure" occurs if a particular institutional structure results in lower net benefits for society compared to an alternative structure. "Transition failure" occurs when the process for changing the structures of institutions achieves a lower cumulative set of net benefits for society compared to an alternative process over a given period. Khan points out that from a political-economy viewpoint a possible and important reason for transition failure is that classes or groups that fear losing out can threaten transition costs that are too high for those proposing the institutional change with the result that potential institutional changes may not occur (Khan 1995, 84). We would add that informal or intangible constraints can also determine high transition costs.

Institutions have been distinguished as formal and informal. The former are enforced by third parties (the state) and include the structure of laws, the rules under which national governments, local governments and all types of financial and economic organizations operate. Informal institutions are rules that are not enforced by third parties but are either self-enforcing or enforced informally. They include conventions, customary practices, norms, rules emanating from culture, religion and so on. Endowments of "social capital", trust and spontaneous sociability referred to earlier, are mainly related to the enforcement of informal institutions, but they also affect the operating and 
enforcement costs of formal institutions.

North (1990) hints at the problems that can emerge in cases where formal rules (institutions) change but the informal institutions underpinning these institutions do not. In such cases, tensions can emerge between informal constraints and new formal rules that may be inconsistent with each other. As North points out, "such change is sometimes possible, in particular in a partial equilibrium context, but it ignores the deep-seated cultural inheritance that underlies many informal constraints. Although a wholesale change in the formal rules may take place, at the same time there will be many informal constraints that have great survival tenacity because they still resolve basic exchange problems among the participants, be they social, political, or economic. The result over time tends to be a restructuring of the overall constraints - in both directions - to produce a new equilibrium that is far less revolutionary" (North 1990, 91). In general, the informal institutions constituting the foundation of society as conventions and norms stabilize social expectations and structure social life. "Because they are self-enforcing, the efficacy of these rules depends on the extent to which social actors find it in their self-interest to comply with them" (Knight 1992, 171).

Informal constraints are potentially important factors determining the direction and pace of institutional changes, because formal institutions are, in general, designed and created on the foundation of informal conventions and norms. But do we have the capacity to precisely predict the direction and pace of change? Our bounded rationality (see Simon 1983) is one factor that constrains us in our understanding of the particular informal constraints at work as stabilizers in a particular context. This type of analysis warns us that there are possibly important informal constraints working to underpin a formal institutional system that we may not be fully aware of. By the same token, formal institutions may be created that lack an appropriate informal structure of norms to make them effective, and they may further weaken a pre-existing informal institutional framework rather than strengthening it.

The assumption that economic agents are rationally self-interested can drive a misleading analysis that suggests that institutional change will be driven in directions that make everyone better off (see Knight 1992, 109). However, for instance, the Prisoner's Dilemma framework in game theory tells us that the dominant strategy of rational self-interested agents can easily be such that a mutually beneficial outcome does not emerge. Just as important, institutional changes are often pursued under conditions of bounded rationality or procedural rationality. We are often incapable of satisfactorily evaluating the collectively beneficial nature of particular social rules, because we have a limited knowledge of the informal constraints that are important for making them work. Transition failure may therefore be related to the cost of changing not only the formal institutions but also the uncertain relationship between formal and informal institutions. 
Under conditions of uncertainty, imperfect information and high transaction costs, the subjective models of economic agents modified both by imperfect feedback and by ideology shapes the path of transition (North 1990).

Apart from the question of the compatibility of particular formal institutions with underlying informal institutions, the sudden abandonment of a system of formal institutions based upon particular relationships of trust can also result in a sudden collapse of trust in the system as a whole that is itself relatively costly. When trust in general is eroded in the system this can make the transition paths (in any direction) more costly because collaboration between agents and organizations in organizing a transition can collapse. The result can be a failure that manifests itself as a trap of "collective inaction" where all agents simply opt to maintain the status quo, whatever it is, because they are unwilling to cooperate with other agencies in a context of collapsing trust. Thus, the collapse of trust in a pre-existing system can actually result in narrowing the path to find alternative institutions.

These insights can help to explain why Japanese banks continued to operate as if the old system was still operational even when the formal rules of a new system began to be introduced by the regulators. Under the traditional "convoy" system, banks facing difficulties expected regulators to come up with initiatives for resolving the non-performing loan problem. These expectations continued and the attempt of regulators to enforce a different set of rules resulted in a loss of trust. One consequence of the loss of trust was that main banks continued to act as if the old system was still in operation, creating a hold-up situation for the regulators. Regulators could respond to the decisions of major banks in ways that would re-establish trust, but if they let main banks collapse according to new rules, trust would be further eroded and main banks would be less willing to accept losses for the collective good. Some aspects of the continuing Japanese financial crisis can be explained in terms of tactics being employed by regulators and main banks as each tried to test the intentions and commitment of the other in a context where the traditional system of monitoring had collapsed together with its relationships of trust.

\section{Concluding comments}

The recent changes in the economic environment facing Japanese firms intensified the uncertainty they faced and could have contributed to undermining the traditional trust relations underpinning economic activities. Nevertheless, the system depended upon a particular set of relationships of mutual trust, and a new system based on a different set of formal and informal rules for monitoring would require a different but effective set of 
constraints for controlling opportunistic behaviour. In the face of new rules and systems of informal constraints (or trust) intended to restrain the emergence of opportunistic behaviour and high transaction costs in the new system, the old system collapsed, and these issues were a fundamental source of the transition failure that Japan faced.

We are not arguing the traditional Japanese system was not viable or that it collapsed only because of policy errors. We can see that Japan went through an economic transition from the "catching-up" period (when Japan's economy enjoyed high economic growth until the mid-1970s) when uncertainty for lenders was primarily based on the possibility of shirking by borrowers, to a "frontier" economy wherein most uncertainty is fundamental and based on uncertainty related to the future marketability of investments in innovation. (In the "catching-up" period when Japan's economy was trying to catch up with the United States, the business model of absorbing and improving engineering know-how absorbed from abroad greatly contributed to Japan's high economic growth. During the subsequent "frontier" economy stage, many Japanese industries were getting close to or even reaching the international technology and marketing frontier). As the Japanese economy matured into a frontier economy, the relationships of trust between main banks and client firms were no longer sufficient for making the system work. Rather, these trust relationships became a systemic contributor to increasing systemic risk by enabling banks to undertake excessive credit risks. The old system of trust-based monitoring was not well suited for limiting exposure when most loans were subject to fundamental uncertainties. What is significant for our assessment of the transition is that while the traditional system had become inappropriate, the Anglo-American system was not necessarily an appropriate transition goal either. The relationships of trust on which the Japanese system was based made it difficult to transit to the Anglo-American system of monitoring in which banks can resort to the legal process for liquidation or corporate reorganization of troubled firms. The fundamental problem in the Japanese transition was that there was an inadequate understanding of the systemic requirements of the Anglo-American financial system.

Japan should have opted for a transition to an alternative system which could socialize and diversify credit risk and uncertainty as the Japanese economy shifted from its "catching-up" phase to becoming a "frontier" economy. In a "frontier" economy, the bank-based indirect finance system has to provide financing for innovation, which is exposed to a different level of uncertainty. However, this could potentially have been achieved in Japan by adapting rules of thumb and rules for operating margins. This argument will not necessarily be accepted by all analysts. While emphasizing "social capital" and "spontaneous sociability" as an important factor for economic organization and growth, Francis Fukuyama points out that social solidarity is not always beneficial from the standpoint of economic well-being (Fukuyama 1995, 139). He refers to 
Schumpeter's phrase, "capitalism is a process of 'creative destruction'," where inefficient organizations have to be modified or eliminated and new ones created in their place. Economic progress demands the constant substitution of one kind of group for the other. Our argument that this process could in principle be mediated through a banking system which would have to be tested in practice through a process of experimentation and adaptation. We cannot definitively prove our case, but we feel there is clear evidence to support the assertion that no attempt was made to adapt the Japanese banking system in this direction to test whether this direction of reform would have been feasible. In our analysis, this represents a major failure for Japan and represents significant lost opportunities for a potentially viable reform path.

\section{Notes}

1 The SMEs' share in the Japanese economy was $99 \%$ in terms of the number of firms (SMEA, 2005 ) and $72.6 \%$ in terms of the number of employees in 2004 (METI 2005). In the manufacturing sector the SMEs' share was around $50.5 \%$ of the overall industrial output and around $56.8 \%$ of the overall value-added (METI 2005).

2 For instance, according to Saito (1998) the continuation of economic policy errors occurred because there was a lack of a "control tower" (a strong political leadership) when it was most needed after the malfunction of the Japanese "convoy" system. However, an important gap in his argument is any explanation of why Japan has continuously failed to create a "control tower" over such a long period. Takeda (2001) criticizes the regulator's insufficient accountability in terms of disclosure of information, in particular, about the process of policy-making. However, as is argued later, transparency does not always resolve the "audience effect" and a relatively closed channel for sharing information between regulators and the banking industry is occasionally required for ensuring financial stability.

3 The term comes from the fact that in convoys, all ships have to match the speed of the slowest ship, so that all reach their destination together. It also alludes to the fact the Ministry of Finance (MOF) provided escort (protection), the point of forming a convoy being so that the cargo ship could be protected efficiently by warships (Hoshi and Kashyap 2001). Under the convoy system (goso sendan hoshiki), even the most inefficient financial institutions were led to grow at the same speed, and protection was provided against failure, for the purpose of maintaining financial stability (see Aoki et al. 1994, 27-30).

4 Fukuyama points out; "If people who have to work together in an enterprise trust one another because they are all operating according to a common set of ethical norms, doing business costs less. Such a society will be better able to innovate organizationally, since the high degree of trust will permit a wide variety of social relationships to emerge. Hence highly sociable Americans pioneered the development of the modern corporation in the late nineteenth and early twentieth centuries, just as the Japanese have explored the possibility of network organizations in the twentieth. By contrast, people who do not trust one another will end up cooperating only under a system of formal rules and regulations, which have to be negotiated, agreed to, litigated and enforced, sometimes by coercive means. This legal apparatus, serving as a substitute for trust, entails what economists call 'transaction costs'. Widespread distrust in a society, in other words, imposes a kind of tax on all forms of economic activity, a tax that high-trust societies do not have to pay" (Fukumaya 1995, 27-28). 
5 “'Main bank' is a practitioners' term used by financial institutions, corporations, and regulators, as in 'Bank X is the main bank of Firm Y' or 'Firm Y has Bank X as its main bank'”. The term 'main bank system' as currently used encompasses not only these corporate financing relationships, but also the various monitoring- and governance-related practices and institutional arrangements that connect industrial and commercial firms, banks and regulatory authorities (see Aoki et al. 1994, 3).

6 Rents refer to "excess incomes" which, in simplistic models, should not exist in efficient markets. it is often said that the stability in the Japanese main bank system was partly achieved by interest rate controls, with a wide spread between deposit and lending rates, so that the major banks could earn profits.

7 While the Liberal Democratic Party (LDP) did propose a plan to recapitalize weak banks and in early July 1998 put forward a proposal to create so-called "bridge banks" that would take direct control over the operations of failed institutions, the Hashimoto Cabinet was unable to translate these proposals into concrete legislative action. 


\section{Reference}

Aoki, M., H. Patrick and P. Sheard. 1994. Introduction: The Japanese Main Bank System: An Introductory Overview. In The Japanese Main Bank System, ed. Aoki, M. and Patrick H., Oxford University Press.

Arrow, K.J. 1974. The Limits of Organization. Norton.

Basle Committee on Baking Supervision (BCBS). 2006. International Convergence of Capital Measurement and Capital Standards: A Revised Framework. Bank for International Settements. June 2006.

Cabinet Office. 2001. Heisei 13 nendo-ban, Keizai Zaisei Hakusho (Annual Report on Japan's Economy and Public Finance 2000-2001). Government of Japan.

Cohen, D. and J.L.Knetsch. 1992. Judicial Choice and Disparities between Measures of Economic Values. In Choices, Values, and Frames, ed. Kahneman. D. and Tversky, A, 2000. Cambridge University Press.

Dore, R. 1998. Asian crisis and the future of the Japanese model. Cambridge Journal of Economics. 22: 773-787.

Dore, R. 2000. Stock Market Capitalism: Welfare Capitalism, Japan and Germany versus the Anglo-Saxons. Oxford University Press.

Eichengreen, B. 1999. Toward a New International Financial Architecture, A Practical Post-Asia Agenda. Institute for International Economics.

Elster, J. 2000. Ulysses Unbound, Studies in Rationality, Precommitment, and Constraints. Cambridge University Press.

Freixas, X. and J.C. Rochet. 1997. Microeconomics of Banking. The MIT Press.

Fukuyama, F. 1995. Trust: The Social Virtues and the Creation of Prosperity. Free Press.

Harada, Y. 1999. Nihon no Ushinawareta 10 nenn. Nihon Keizai Shimbun Sha.

Hellmann, T., K. Murdock and J. Stiglitz. 1997. Financial Restraint: Toward a New Paradigm. In The Role of Government in East Asian Economic Development: Comparative Institutional Analysis. ed. Aoki, M., Kim, H-K. and Okuno-Fujiwara, M. Oxford: Clarendon Press.

Hoshi, T. and A. Kashyap. 2001. Corporate financing and governance in Japan: The road to the future. The MIT Press.

Ikeo, K. 2006. Kaihatsu Shugi no Boso to Hosin. NTT Shuppan.

JSBRI (Japan Small Business Research Institute). 2009. 2009 White Paper on Small and Medium Enterprise in Japan. Tokyo.

Khan, M. 1995. State Failure in Weak State: A Critique of New Institutionalist Explanations. In The New Institutional Economics and Third World Development. ed. J.Hunter, J.Harriss and C.Lewis. London:Routledge. 
Kindleberger, C. 2000. Manias, Panics and Crashes: $3^{\text {rd }}$ and 4th edition. London and Basingstoke, Macmillan.

Knight, J. 1992. Institutions and Social Conflict. Cambridge University Press.

METI (Ministry of Economy, Trade and Industry). 2005. Heisei 15 nen Kogyo Tokei Hyo (Industrial statistics in 2003).

Nishimura, Y. 1999. Kinyu-Gyosei no Haiin. Bunshun.

North, D.C. 1990. Institutions, Institutional Change and Economic Performance. Cambridge University Press.

Okazaki T. 1995. Sengo nihon no kinyu shisutemu. In Nihon Keiei-shi 5. ed. Morikawa, H. and Yonekura, S. Iwanami.

Okuno-Fujiwara, M. 1997. Toward a Comparative Institutional Analysis of the Government-Business Relationship. In The Role of Government in East Asian Economic Development: Comparative institutional Analysis. ed. Aoki,M., Kim,H-K and Okuno-Fujiwara, M. Oxford: Clarendon Press.

Okuno-Fujiwara, M. 2002. Baburu Keizai to Sono Hatan Shori. In Heisei Baburu no Kenkyu (Jyou). ed. M. Okuno-Fujiwara. Toyo Keizai Shimpo Sha.

Patrick, H. 1998. The Causes of Japan's Financial Crisis, prepared for Conference on Financial Reform in Japan and Australia. The Australia National University.

Saito, S. 1998. 10 nen Defure. Nihon Keizai Shimbun Sha.

Simon, H.A. 1983. Alternative visions of rationality. In Rationality in Action: Contemporary approaches. ed. Moser, P.K.Moser. Cambridge University Press.

SMEA (Small and Medium Enterprise Agency). 2005. 2005 Nendo Chusho Kigyo Hakusho (White Paper).

Stiglitz, J. 1994. Whither Socialism?. The MIT Press.

Takeda, S. 2001. Shinyo to shinrai no keizai gaku. NHK Books.

Toya, T. 2003. Kinyuu Big Bang no Seiji Keizai Gaku (The Political Economy of the Japanese Financial Big Bang). Toyo Keizai Shimpou-Sha.

Tsuru, K. 2006. Nihon no Keizai Shisutemu Kaikaku. Nihon Keizai Shimbun Sha.

Uriu, R. 1999. Japan in 1998: Nowhere to Go but Up?. Asian Survey. 39(1): 114-124.

Williamson, O.E. 1985. The Economic Institutions of Capitalism. The Free Press.

Yoshikawa, H. 1999. Tenkanki no Nihon Keizai. Iwanami.

Yoshikawa, H. 2003. Kozo Kaikaku to Nihon Keizai. Iwanami. 